\title{
FIRST DETECTION OF HEAT SHOCK PROTEIN 60 AND 70 IN THE SERUM OF EARLY PREGNANT BITCHES
}

\author{
Sabine SCHÄFER-SOMI ${ }^{1 *}$, Okan Ali AKSOY ${ }^{2}$, Osman ERGENE $^{3}$, Isfendiyar DARBAZ ${ }^{3}$, \\ Kurt R. HERKNER ${ }^{3}$ and Selim ASLAN ${ }^{4}$ \\ ${ }^{1}$ Centre for Artificial Insemination and Embryo Transfer, University of Veterinary \\ Medicine Vienna, Veterinärplatz 1, A-1210 Vienna, Austria; ${ }^{2}$ Department of Animal \\ Experiment and Research Centre, Gülhane Institute of Health Sciences, University of \\ Health Sciences, Turkey, Ankara; ${ }^{3}$ Department of Paediatrics and Adolescent Medicine, \\ Medical University Vienna, Austria; ${ }^{4}$ Department of Obstetrics and Gynaecology, \\ Veterinary Faculty, Near East University, Nicosia, Mersin-10, Turkey
}

(Received 12 February 2019; accepted 31 July 2019)

\begin{abstract}
Heat shock proteins (HSPs) belong to a group of cellular stress proteins. Heat shock protein 10 immunoregulates and promotes growth during early gestation in humans, while HSP70 is considered to regulate autophagy and apoptosis during pregnancy and parturition. Both HSPs are detectable in the serum and placentas of early pregnant women and considered to contribute to the establishment of pregnancy. Within this pilot study we aimed (1) to assess whether HSPs 10, 60 and 70 are measurable in the serum of healthy early pregnant and non-pregnant bitches, and (2) to explore whether measurable differences between groups indicate pregnancy. Blood was collected from 31 bitches on days 7, 14 and 21 after mating. At 21 days post mating, all bitches were examined for pregnancy by ultrasonography; 23 were pregnant, and the eight non-pregnant bitches served as controls. Pregnant bitches had normal parturitions and gave birth to healthy puppies. The serum concentrations of HSPs 10, 60 and 70 were measured by electrophoresis and western blot. Serum HSP10 was not detectable. Average serum HSP70 concentration was significantly $(\mathrm{d} 7, \mathrm{P}=0.030 ; \mathrm{d} 14, \mathrm{P}=0.023 ; \mathrm{d} 21, \mathrm{P}=$ 0.030 ) lower in pregnant animals at all days investigated, while serum HSP60 was significantly lower at day 21 of gestation $(\mathrm{P}=0.024)$ when compared to the controls. HSP 60 and HSP70 concentrations correlated positively $(\mathrm{d} 7, \mathrm{r}=+0.386, \mathrm{P}=$ $0.021 ; \mathrm{d} 14, \mathrm{r}=0.450, \mathrm{P}=0.008 ; \mathrm{d} 21, \mathrm{r}=+0.472, \mathrm{P}=0.006)$. We conclude that in pregnant bitches, serum concentrations of HSP60 and HSP70 are significantly decreased between days 7 and 21 of gestation, in comparison to non-pregnant bitches in early dioestrus, raising the question about intrauterine functions during the peri-implantation period.
\end{abstract}

Key words: Dog, pregnancy, embryo, implantation, heat shock proteins

\footnotetext{
*Corresponding author; E-mail: sabine.schaefer@vetmeduni.ac.at; Phone: 0043 (1) 25077-6416; Fax: 0043 (1) 25077-5490
} 
In dogs, the investigation of early pregnancy is a field of growing interest (Schäfer-Somi et al., 2008; Kautz et al., 2014; Kowalewski et al., 2015; Graubner et al., 2017; Szczubial et al., 2017; Valdés et al., 2019). Besides the wish to shed light on the physiology and pathology of canine pregnancy, the wish for the early detection of pregnancy is a trigger since it may among others help to prevent unnecessary treatments in case of unwanted matings.

At present, relaxin, a hormone of placental origin, secreted by fetal syncytiotrophoblast cells, is the only reliable marker of pregnancy in the bitch (Klonisch et al., 1999). Relaxin is measureable in the serum from day 19 after the LH peak on (Buff et al., 2001).

In the serum of pregnant bitches, the acute phase protein (APP) C-reactive protein (CRP) was found to be significantly increased in comparison to nonpregnant controls from mid-gestation on (Concannon et al., 1996; Kuribayashi et al., 2003; Sacks et al., 2004; Holst et al., 2019). Furthermore, the fibrinogen concentration is increased in pregnant bitches compared to those in dioestrus from day 28 after the LH surge (Concannon et al., 1996; Vannucchi et al., 2002; Ulutas et al., 2009). Serum proteomic studies revealed the significant elevation or decrease of further proteins in pregnant bitches during the peri-implantation period (Szczubial et al., 2017; Valdés et al., 2019); this concerned mainly immunoglobulins and proteins known to participate in inflammation and coagulation, while further proteins were found in variable concentrations in pregnant bitches.

Chaperonins or heat shock proteins (HSPs) are highly conserved cellular stress proteins. They fulfil functions like protein folding after cellular stress, transport and assembling of proteins, and degradation (Gething and Sambrook, 1992). Chaperonin 10 (HSP10) present in the serum of pregnant women has immunosuppressive and growth promoting effects (Cavanagh, 1996). Heat shock proteins 60 and 70, present in mitochondria, stimulate cytokine secretion (Neuer et al., 2000; Pockley, 2003) and are among others responsible for protein folding and stabilisation. Intracellular HSP70 protects cells from detrimental influences, especially during phases of accelerated cell mitosis like early pregnancy (Hansen, 2007). Changed serum concentrations of HSP60 and 70 might indicate pathological utero-placental conditions (Makri et al., 2019). In dogs, HSPs are mainly investigated as indicators of inflammatory and tumorous diseases (Okada et al., 2015; Bruchim et al., 2017). There are no studies investigating their local expression in uterine or placental tissue or their concentration in the serum of pregnant bitches. Within this pilot study we therefore aimed to assess whether (1) HSP10, 60 and 70 are detectable in the serum of bitches, and (2) a significant difference in the serum of pregnant and non-pregnant bitches can be measured earlier than other factors. The hypothesis was that HSPs fulfil special functions inside the canine uterus during the establishment of pregnancy which could be reflected in their changed serum concentrations. Heat shock proteins thus might indicate pregnancy earlier than other factors. 


\section{Materials and methods}

\section{Animals and sampling}

Within this explorative pilot study 31 bitches of different breeds were available; all were patients of the Clinic for Reproduction, Faculty of Veterinary Medicine, University of Ankara (TR), introduced for neutering after an unwanted mating. The age ranged from 1 to 5 years and the body weight from 15 to $35 \mathrm{~kg}$. A clinical examination, complete blood count and serum chemistry were done when the dogs were first presented. Only healthy animals with normal blood values and without clinical signs of inflammatory diseases, tumours or organ insufficiencies were included in the experiment. Blood was collected starting from 57 days after the last mating, as indicated by the owner. All bitches were examined by vaginoscopy and vaginal cytology for health and to assess the stage of the sexual cycle. Further blood samples were taken at days 14 and 21 after mating. After day 21 all bitches were sonographically examined for pregnancy by an experienced examiner (Pie Medical ${ }^{\circledR}, 6$ and $8 \mathrm{MHz}$ probes, Maastricht, the Netherlands); 23 bitches were found to be pregnant and 8 non-pregnant. The fetuses and placentas were examined sonographically, and after parturition the number of puppies was recorded. The study protocol was approved by the local ethics committee of the Faculty of Veterinary Medicine, Ankara University, Turkey (2007/15).

\section{Progesterone and oestrogen measurement}

Blood samples were centrifuged for $3 \mathrm{~min}$ at $3000 \mathrm{~g}$ and the sera stored at $-18{ }^{\circ} \mathrm{C}$ until analysis. To verify normal endocrine conditions during gestation and dioestrus, respectively, serum concentrations of progesterone $(\mathrm{P} 4, \mathrm{ng} / \mathrm{ml})$ and oestrogen $(\mathrm{E} 2, \mathrm{pg} / \mathrm{ml})$ were measured in duplicate using the Electrochemiluminescence Immunoassay (ECLIA) with a fully automated Cobas Modular E170 Analyser (Roche Diagnostics, Mannheim, Germany) as described before (Agaoglu et al., 2011).

\section{Western blot}

For 1D electrophoresis of serum, precast gels from GE Healthcare (Uppsala, Sweden) were used. The standard material (Precision Plus Protein ${ }^{\mathrm{TM}}$ Standard, All Blue) was from Bio-Rad (Munich, Germany).

Western blot was performed on PVDF membranes (Millipore, Billerica, Ireland) with a pore size of $0.45 \mu \mathrm{m}$ in a semi-dry blotting transfer system (filter paper: GE Healthcare, Uppsala, Sweden). Removal of gel from the carrier was performed with a film remover (Pharmacia LKB, Uppsala, Sweden). Western blot was performed with $5 \mathrm{~V}, 107 \mathrm{~mA}$ and $10 \mathrm{~W}$ for $1 \mathrm{~h}$. The membrane was 
washed twice with TBST (Tris Base $6.05 \mathrm{~g}, \mathrm{NaCl} 8.7 \mathrm{~g}$, Tween $201 \mathrm{~g}$; ad $900 \mathrm{ml}$ distilled water $\mathrm{pH} 7.4$ with $\mathrm{HCl}$ ) and stored to dry overnight.

For the immunological detection of HSP10, 60 and 70, the membrane was blocked with $5 \%$ dry milk (Bio-Rad, CA, USA) for $2 \mathrm{~h}$ at room temperature, and then washed twice with TBST for $10 \mathrm{~min}$. The membrane was incubated overnight with specific antibodies (see below; dilution 1:4000 with 1\% dry milk solution (with TBST). Membranes were washed 4 times with TBST for 10 min, and then incubated with the secondary antibody $(\mathrm{Ab})$ after dilution 1:2000 with $1 \%$ dry milk (with TBST). After $2.5 \mathrm{~h}$ of incubation at room temperature, the membrane was washed 4 times with TBST for 10 min each.

HSP10. Primary Ab: Cpn10 polyclonal antibody (Assay Designs, Michigan, USA); Secondary Ab: goat-anti-rabbit (Santa Cruz Biotechnology, Santa Cruz, USA). Since two bands were detected during the first run of the assay (60 and $90 \mathrm{kD}$ ), unspecific cross-reactions were suspected. To assess whether the here used $\mathrm{Ab}$ was damaged or not specific enough, several controls were used; however, no bands were detectable. (1) Human mesothelial cells were stimulated and then incubated with the HSP10 Ab. (2) Bovine serum albumin (Bio-Rad, CA, USA) was used instead of non-fat dry milk (Bio-Rad, CA, USA). (3) HeLa Cell Lysate (HeLa Cell Lysate, Assay Designs, Michigan, USA) was stimulated and used as positive control $(5,10,15 \mu 1)$ and diluted $1: 1$ with X buffer $(150 \mathrm{mM}$ Tris $\mathrm{HCl} \mathrm{pH} \mathrm{7.5;} 14 \%$ glycerol; $0.0025 \%$ bromophenol blue (BPB); $10 \%$ SDS : $10 \%$ mercaptoethanol - all diluted 1:1 with double-distilled water). (4) The same HeLa cell lysates and a protocol of the manufacturer of the HSP10 Ab (Assay Designs, Michigan, USA) were used. Primary Ab: dilution 1:1000 (20 ml 5\% milk $+20 \mu \mathrm{l} \mathrm{Ab}$ ), incubation at room temperature for $1 \mathrm{~h}$. Secondary Ab: dilution 1:1000 (20 ml 5\% milk $+20 \mu \mathrm{Ab})$, incubation at room temperature for $1 \mathrm{~h}$. The gel was cut into two halves; one half was blotted and incubated with the Ab, the second half was stained with silver to visualise the proteins. Standard solution (Precision Plus Protein ${ }^{\mathrm{TM}}$ Standard, All Blue, Bio-Rad, CA, USA; $8 \mu 1$ ), a sample and the pure HeLa lysate $(5 \mu \mathrm{l})$ were incubated together. Blocking with $5 \%$ dry milk was done overnight at $+4{ }^{\circ} \mathrm{C}$. Washing was performed twice with PBS (25 ml 40× PBS with $1000 \mathrm{ml}$ distilled water $+0.5 \mathrm{~g}$ Tween). (5) A membrane with $0.22 \mu \mathrm{m}$ pore width was used instead of $0.45 \mu \mathrm{m}$ together with the protocol described above (4). Bands were now visible with the HeLa cell lysate but not with the serum samples.

HSP60/70. Primary Ab: HSP60 monoclonal antibody (Assay Designs SPA-829F, Michigan, USA). Secondary Ab: polyclonal rabbit anti-mouse immunoglobulins/HRP, 1.3 g/l (Dako, Glostrup, Denmark). Primary Ab: HSP70 (HSP72) monoclonal Ab (Assay Designs SPA-810F, Michigan, USA). Secondary $\mathrm{Ab}$ : anti-mouse-IgG-HRP, polyclonal rabbit (Dako Cytomation, Glostrup, Denmark). The method was the same as for HSP10. Since with HSP60 some bands were overloaded with proteins, a dot blot was performed. 


\section{Dot blot}

Because of the evolutionary high conservation of HSPs (Sørensen et al., 2003), recombinant human HSP60 (H7158, Sigma Aldrich, Vienna, Austria) was used. Dot blot was performed with Prime Western Blotting Reagents Solution A + B (Amersham ECL, Uppsala, Sweden). Serum samples were diluted with distilled water 1:30, 1:100, 1:500, 1:1000 and 1:2000. A PVDF membrane (Millipore, $0.45 \mu \mathrm{m}$ pore width) was incubated with methanol for $1 \mathrm{~min}$, then washed ( $2 \times 5 \mathrm{~min})$. After drying the membrane, $10 \mu \mathrm{l}$ of each serum dilution was deposited on the membrane and incubated for $1 \mathrm{~h}$ at room temperature. The membrane was moisturised with methanol and washed $(2 \times 5$ min with TBST). Blocking was done with $5 \%$ dry milk overnight and the membrane was washed with TBST $(2 \times 5 \mathrm{~min})$. Samples were incubated for $1 \mathrm{~h}$ at $37^{\circ} \mathrm{C}$ with the primary $\mathrm{Ab}$ (dilution 1:4000 with $1 \%$ milk), and after washing with TBST $(4 \times 10 \mathrm{~min})$ with the secondary $\mathrm{Ab}$ (dilution 1:2000 with 1\% milk). Membranes were swayed for 5 min in an electrochemiluminescence (ECL) solution (ECL Plus Western Blotting Detection Reagents, GE Healthcare, Amersham, UK). A serum dilution of 1:500 proved to be best.

\section{D-Electrophoresis}

Twelve immobilised pH 3-10 non-linear gradient stripes (IPG, Immobiline Dry Strip, pH 3-10, $11 \mathrm{~cm}$, Cat. No. 18-1016-61; GE Healthcare Bio-Science AB, Uppsala, Sweden) were used. Serum samples were diluted 1:10 with distilled water and $100 \mu 1$ per sample were deposited at the basic and acidic end of each strip. Focusing was started at $100 \mathrm{~V}$ and gradually increased to $3500 \mathrm{~V}$ over $4 \mathrm{~h}$ and kept at that voltage for further $2.5 \mathrm{~h}$. Strips were stored at $-80^{\circ} \mathrm{C}$. Strips were equilibrated for $15 \mathrm{~min}$ in dithiothreitol (DDT) buffer (100 mg DDT + $10 \mathrm{ml}$ equilibration buffer) and for further $15 \mathrm{~min}$ in iodine-acetate-amide (IAA) buffer (480 mg IAA $+10 \mathrm{ml}$ equilibration buffer). Buffer composition: urea, $396 \mathrm{~g}$; glycerol, $300 \mathrm{~g}$; SDS, $20 \mathrm{~g}$; bromophenol blue, $9 \mathrm{mg} ; 1.5 \mathrm{M}$ Tris-HCl buffer, $36 \mathrm{ml}$; $\mathrm{pH} 8.8$ ad $1000 \mathrm{ml}$ distilled water). After equilibration, strips were placed on the electrophoresis gel (12.5\% PAGE) and the second dimension run was performed $(100 \mathrm{~V}, 30 \mathrm{~min} ; 500 \mathrm{~V}, 1.35 \mathrm{~h})$. Gels were fixed overnight with ethanol (40\%, $100 \mathrm{ml})$ and acetic acid $(10 \% 12 \mathrm{ml})$, in distilled water ad $250 \mathrm{ml}$.

\section{Statistical analyses}

All data were calculated with SPSS Win 17.0. All values are given as means \pm standard deviation $(\mathrm{x} \pm \mathrm{SD})$. The average for each day was calculated for each group (pregnant/non-pregnant) and each parameter, and the course was evaluated by a non-parametric one-way ANOVA (Friedman test). In case of significance, differences between groups (pregnant and non-pregnant) and days were proven by means of pairwise post-hoc tests (Mann-Whitney U test). Correlations 
between the number of puppies and HSP concentrations were calculated by means of Spearman's rank correlation. A P value of $<0.05$ was considered statistically significant.

\section{Results}

\section{Clinical findings and serum hormone concentrations}

All bitches were found healthy, and clinically, cytologically and endocrinologically in the stage of early dioestrus when sampling started. Sonographic examination of non-pregnant bitches at day 21 did not reveal any cause for the failure to conceive. Sonographic examination of pregnant bitches at day 21 showed normally developed embryos and placentas. The concentration of P4 and E2 was in the range considered normal (Concannon et al., 1975, 1977, 2001) between days 7 and 21 of canine gestation and dioestrus, respectively (P4, pregnant vs. non-pregnant, $\mathrm{ng} / \mathrm{ml}$ : day $7: 27 \pm 1.4$ vs. $1.7 \pm 7.8$; day $14: 24.3 \pm 2.9$ vs. $22.8 \pm$ 8.7; day $21: 21 \pm 2.8$ vs. $19.2 \pm 8.5$; E2, pregnant vs. non-pregnant, $\mathrm{pg} / \mathrm{ml}$ : day 7 : $20.3 \pm 1.5$ vs. $21.9 \pm 5.7$; day $14: 23.5 \pm 2.5$ vs. $31 \pm 4.7$; day $21: 23.8 \pm 1.3$ vs. $30.2 \pm 16.8$ ). All pregnant bitches had normal parturitions, and the number of puppies per bitch varied between one and $14(5.5 \pm 4.1)$.

\section{Heat shock proteins}

HSP10 was not detected with any method and in any sample. Concerning HSP60, no significant differences were found between sampling days. However, there was an effect of pregnancy; at all days, HSP60 serum concentrations of the pregnant bitches were lower than those from the non-pregnant controls, and this difference was significant at day 21 of gestation $(\mathrm{P}=0.024$; Fig. 1). When the statistical calculation was repeated one-sided, differences were significant at all days investigated (day 7, $\mathrm{P}=0.030$; day $14, \mathrm{P}=0.026$; day $21, \mathrm{P}=0.012$ ). HSP60 serum concentrations always correlated positively with the HSP70 values $(\mathrm{n}=31$; day $7, \mathrm{r}=+0.386, \mathrm{P}=0.021$; day $14, \mathrm{r}=+0.450, \mathrm{P}=0.008$; day $21, \mathrm{r}=$ $+0.472, \mathrm{P}=0.006)$.

In pregnant bitches, the HSP60 concentrations did not correlate with the number of puppies born at any of the days investigated.

The serum HSP70 concentration did not change during the experimental period in either group; however, in pregnant bitches the HSP70 concentration was always significantly lower than in the non-pregnant controls (day $7, \mathrm{P}=$ 0.030 ; day $14, \mathrm{P}=0.023$; day $21, \mathrm{P}=0.030$ ), at all days (see Fig. 2 ). The HSP70 concentrations during pregnancy did not correlate with the number of puppies born at any of the days investigated.

When the average ratio between HSP60 and HSP70 was calculated, the ratio was higher in pregnant animals (day 7, $1.8 \pm 1.2$; day 14, $1.7 \pm 1.1$; day 21, 
$1.8 \pm 1.0$ ) than in non-pregnant animals (day 7, $0.9 \pm 1.0$; day $14,1.0 \pm 1.1$; day 21 , $0.9 \pm 1.3)$ at all days investigated. The difference was significant at day $21(\mathrm{P}=$ $0.034)$.

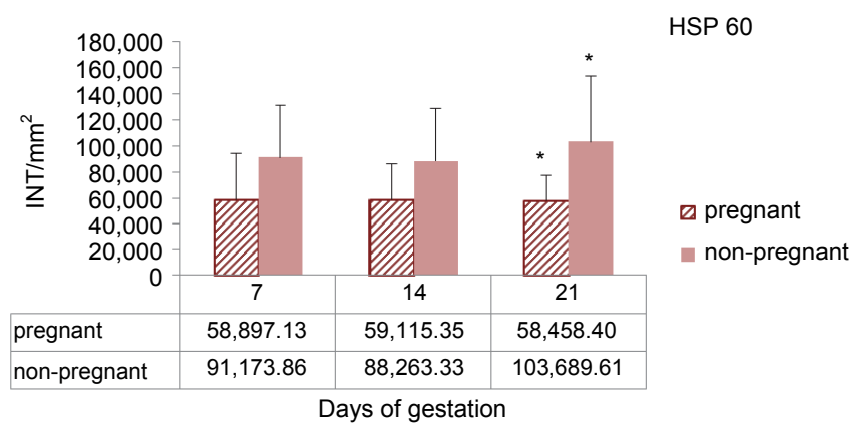

Fig. 1. Serum concentration of HSP60 in pregnant and non-pregnant bitches. Blood samples were taken at days 7, 14 and 21 after mating from pregnant and non-pregnant bitches. HSP60 concentration was measured by electrophoresis and western blot. Values in the tables are average values; in the graph, values are given as $\mathrm{x}+\mathrm{SD}$. ${ }^{*}$ Superscripts indicate significant difference between groups $(\mathrm{P}<0.05)$

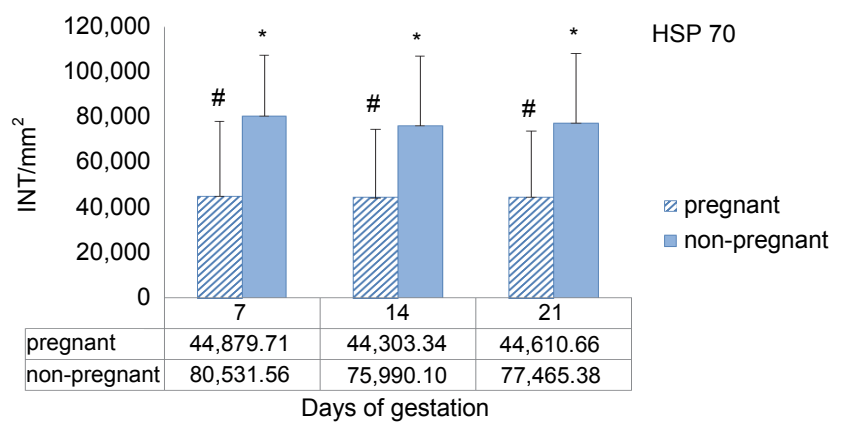

Fig. 2. Serum concentration of HSP70 in pregnant and non-pregnant bitches. Blood samples were taken at days 7, 14 and 21 after mating from pregnant and non-pregnant bitches. HSP70 concentration was measured by electrophoresis and western blot. Values in the tables are average values; in the graph, values are given as $\mathrm{x}+\mathrm{SD} .{ }^{*}, \#$ Bars with different superscripts differ significantly

$$
(\mathrm{P}<0.05)
$$

\section{Discussion}

The aim of this study was to detect HSP10, 60 and 70 in the serum of early pregnant bitches. Despite all efforts, HSP10 could not be detected in any sample. First we stimulated human mesothelial cells and incubated them with the HSP10 Ab; then we used bovine serum albumin instead of non-fat dry milk; we used different amounts of stimulated HeLa cell lysate as positive control; we tried the same HeLa Cell lysates and a protocol recommended by the manufacturer of the HSP10 Ab. Finally, a membrane with different pore width was used; 
however, no bands were seen with canine serum. A possible reason could be that the chosen antibody Cpn-10 was not suitable; follow-up studies with other antibodies and binding sites should clarify this, which was not possible when the study was initiated.

From day 7 after mating onwards we measured lower concentrations of HSP70 in pregnant animals than in the non-pregnant controls. We suppose that this reflects a decrease in local production (Hansen, 2007). HSP60 and 70 stimulate cytokine secretion and regulate the assembly, conformation and transport of proteins into mitochondria, especially during phases of intense mitosis (Neuer et al., 2000; Pockley, 2003; Witkin et al., 2017). In humans, especially HSP70 is considered to participate in the regulation of autophagy in pregnancy and parturition (Witkin et al., 2017). During the preimplantation period, the embryo is sensitive to oxidative stress, free radicals or high temperatures. Intracellular HSP70 provides cell protection; however, increased secretion probably indicates pathological conditions. Increased HSP70 mRNA concentrations in the serum of pregnant women were related to maternal and placental stress; in women with gestational hypertension and pre-eclampsia, mRNA levels of HSP70 were significantly increased (Hromadnikova et al., 2016). During normal pregnancies, HSP70 might function as an apoptosis-regulating factor. HSP70 inhibits apoptosis by blocking apoptosis-signal regulating kinase 1 (Gao et al., 2010). When HSP70 was blocked in cultured human first trimester trophoblast cells, MMP-2 accumulation and an increase in apoptosis was induced (Jain et al., 2017). An upregulation of FAS and FAS-L mRNA (Schäfer-Somi et al., 2012) and a significant increase in MMP-2 activity (Beceriklisoy et al., 2007) was detected in the uterine tissue of pregnant bitches during the peri-implantation period, indicating intense tissue remodelling. Decreased HSP70 secretion during early gestation could be related to the controlled increase in apoptosis considered essential for trophoblast cell invasion of maternal tissue. A recent study using an in vitro model with cytotrophoblastic JEG-3 cells showed that preimplantation factor PIF, secreted by preimplantation embryos, reduces HSP70 secretion (Hakam et al., 2017); the embryo thereby probably prepares and facilitates consecutive cell invasion.

On day 21 of gestation, we measured significantly lower concentrations of HSP60 in the serum of pregnant bitches than in that of the controls; however, when the statistical test was repeated one-sided, differences were significant at all days investigated, similar to the HSP70 results. We therefore suppose similar functions of HSP 60 and 70 which are furthermore indicated by the correlation between both factors until day 21. In pregnant women, the HSP60/HSP70 ratio was calculated and a significant increase in the ratio was observed in cases of miscarriage, supposedly due to an increase in the tissue release of HSP60 (Makri et al., 2019). We therefore calculated the same ratio in pregnant and nonpregnant bitches. The average HSP60/HSP70 ratio was always higher in pregnant animals and the values stayed constant over the experimental period in un- 
disturbed canine pregnancies. It will be interesting to investigate the ratio in spontaneous and induced abortions.

During recent proteomic studies using the serum of early pregnant bitches, proteins strongly changing during early pregnancy were assessed by means of nano-liquid chromatography-mass spectrometry (Szczubial et al., 2017; Valdés et al., 2019); some proteins were deeper investigated since they showed altered abundance in the serum of pregnant bitches and because of their concentration and known importance during early canine pregnancy. Heat shock proteins were not mentioned. These proteomic studies are, however, limited by low patient numbers (Szczubial et al., 2017: 4 pregnant, 4 non-pregnant; Valdés et al., 2019: 9 pregnant, 7 non-pregnant). We therefore wondered whether the use of a strict methodical filter in such a small patient pool might have veiled relevant changes in the blood of pregnant bitches, like the increase in matrix-metalloproteinase 2 and 9 activity in the serum of early pregnant bitches (Schäfer-Somi et al., 2005). We suppose that proteomic studies do not offer a satisfying and complete screening of the in vivo situation.

We observed for the first time the concentration changes of HSP60 and HSP70 in the serum of healthy pregnant and non-pregnant bitches. Considering the supposed function for the establishment of pregnancy in other species and the significantly lower serum concentrations in pregnant than in non-pregnant bitches, our results highlight a possible role of HSP60 and HSP70 during the establishment of canine pregnancy. The significantly decreased values found from day 7 on make both factors interesting for early pregnancy detection, which has to be verified on a higher patient number. Future studies should furthermore investigate the local expression of HSP60 and HSP70 in relation to further apoptosisregulating factors in the pregnant canine uterus during both physiological and disturbed pregnancies.

\section{Acknowledgements}

We are grateful for the technical support received from the laboratory staff of the Department of Paediatrics and Adolescent Medicine, Medical University Vienna, Austria.

\section{References}

Agaoglu, A. R., Schäfer-Somi, S., Kaya, D., Kucukaslan, I., Emre, B., Gultiken, N., Mulazımoglu, B. S., Colak, A. and Aslan, S. (2011): The intravaginal application of misoprostol improves induction of abortion with aglepristone. Theriogenology 76, 74-82.

Beceriklisoy, H. B., Walter, I., Schäfer-Somi, S., Miller, I., Kanca, H., Izgür, H. and Aslan, S. (2007): Matrix metalloproteinase (MMP)-2 and MMP-9 activity in the canine uterus before and during placentation. Reprod. Dom. Anim. 42, 654-659.

Bruchim, Y., Avital, Y., Horowitz, M., Mazaki-Tovi, M., Aroch, I. and Segev, G. (2017): Urinary heat shock protein 72 as a biomarker of acute kidney injury in dogs. Vet. J. 225, 32-34. 
Buff, S., Fontbonne, A., Lopez, P., Rauer, M. and Crevat, D. (2001): Circulating relaxin concentrations in pregnant and nonpregnant bitches: evaluation of a new enzymeimmunoassay for determination of pregnancy. J. Reprod. Fertil. Suppl. 57, 187-191.

Cavanagh, A. C. (1996): Identification of early pregnancy factor as chaperonin 10: implications for understanding its role. Rev. Reprod. 1, 28-32.

Concannon, P. W., Gimpel, T., Newton, L. and Castracane, V. D. (1996): Postimplantation increase in plasma fibrinogen concentration with increase in relaxin concentration in pregnant dogs. Am. J. Vet. Res. 57, 1382-1385.

Concannon, P. W., Hansel, W. and Visek, W. (1975): The ovarian cycle of the bitch; plasma estrogen, LH and progesterone. Biol. Reprod. 13, 112-121.

Concannon, P. W., Powers, M. E., Holder, W. and Hansel, W. (1977): Pregnancy and parturition in the bitch. Biol. Reprod. 16, 517-526.

Concannon, P., Tsutsui, T. and Shill, V. (2001): Embryo development, hormonal requirements and maternal responses during canine pregnancy. J. Reprod. Fertil. Suppl. 57, 169-179.

Gao, Y., Han, C., Huang, H., Xin, Y., Xu, Y., Luo, L. and Yin, Z. (2010): Heat shock protein 70 together with its co-chaperone CHIP inhibits TNF-alpha induced apoptosis by promoting proteasomal degradation of apoptosis signal-regulating kinase 1. Apoptosis 15, 822-833.

Gething, M. J. and Sambrook, J. (1992): Protein folding in the cell. Nature 335, 33-45.

Graubner, F. R., Gram, A., Kautz, E., Bauersachs, S., Aslan, S., Agaoglu, A. R., Boos, A. and Kowalewski, M. P. (2017): Uterine responses to early pre-attachment embryos in the domestic dog and comparisons with other domestic animal species. Biol. Reprod. 97, 197-216.

Hakam, M. S., Miranda-Sayago, J. M., Hayrabedyan, S., Todorova, K., Spencer, P. S., Jabeen, A., Barnea, E. R. and Fernandez, N. (2017): Preimplantation Factor (PIF) promotes HLA-G, E, -F, -C expression in JEG-3 choriocarcinoma cells and endogenous progesterone activity. Cell Physiol. Biochem. 43, 2277-2296.

Hansen, P. J. (2007): To be or not to be - determinants of embryonic survival following heat shock. Theriogenology 68, 40-48.

Holst, B. S., Gustavsson, M. H., Johannisson, A., Hillström, A., Strage, E., Olsson, U., Axnér, E. and Lilliehöök, I. (2019): Inflammatory changes during canine pregnancy. Theriogenology 125, 285-292.

Hromadnikova, I., Dvorakova, L., Kotlabova, K., Kestlerova, A., Hympanova, L., Novotna, V., Doucha, J. and Krofta, L. (2016): Circulating heat shock protein mRNA profile in gestational hypertension, pre-eclampsia \& foetal growth restriction. Indian J. Med. Res. 144, 229-237.

Jain, C. V., Jessmon, P., Barrak, C. T., Bolnick, A. D., Kilburn, B. A., Hertz, M. and Armant, D. R. (2017): Trophoblast survival signaling during human placentation requires HSP70 activation of MMP2-mediated HBEGF shedding. Cell Death Differ. 24, 1772-1783.

Kautz, E., Gram, A., Aslan, S., Ay, S. S., Selçuk, M., Kanca, H., Koldaş, E., Akal, E., Karakaş, K., Findik, M., Boos, A. and Kowalewski, M. P. (2014): Expression of genes involved in the embryo-maternal interaction in the early-pregnant canine uterus. Reproduction 147, 703-717.

Klonisch, T., Hombach-Klonisch, S., Froehlich, C., Kauffold, J., Steger, K., Steinetz, B. G. and Fischer, B. (1999): Canine preprorelaxin: nucleic acid sequence and localization within the canine placenta. Biol. Reprod. 60, 551-557.

Kowalewski, M. P., Gram, A., Kautz, E. and Graubner, F. R. (2015): The dog: nonconformist, not only in maternal recognition signaling. Adv. Anat. Embryol. Cell. Biol. 216, 215-237.

Kuribayashi, T., Shimada, T., Matsumoto, M., Kawato, K., Honjyo, T., Fukuyama, M., Yamamoto, Y. and Yamamoto, S. (2003): Determination of serum C-reactive protein (CRP) in healthy beagle dogs of various ages and pregnant beagle dogs. Exp. Anim. 52, 387-390.

Makri, A., Siristatidis, C., Chrelias, C., Christodoulaki, C., Evangelinakis, N., Kassanos, D., Giamarellos-Bourboulis, E. J. and Pistiki, A. (2019): Early changes of the heat-shock protein 60 to 70 ratio as prediction of miscarriage in pregnancy. Am. J. Reprod. Immunol. 4e, 13087. 
Neuer, A., Spandorfer, S. D., Giraldo, P., Dieterle, S., Rosenwaks, Z. and Witkins, S. (2000): The role of heat shock proteins in reproduction. Hum. Reprod. Update 6, 149-159.

Okada, S., Furuya, M., Takenaka, S., Fukui, A., Matsubayashi, M., Tani, H. and Sasai, K. (2015): Localization of heat shock protein 110 in canine mammary gland tumors. Vet. Immunol. Immunopathol. 167, 139-146.

Pockley, G. (2003): Heat shock proteins as regulators of the immune response. The Lancet 362, 469-479.

Sacks, G. P., Seyani, L., Lavery, S. and Trew, G. (2004): Maternal C-reactive protein levels are raised at 4 weeks gestation. Hum. Reprod. 19, 1025-1030.

Schäfer-Somi, S., Ali Aksoy, O., Patzl, M., Findik, M., Erunal-Maral, N., Beceriklisoy, H. B., Polat, B. and Aslan, S. (2005): The activity of matrix metalloproteinase-2 and -9 in serum of pregnant and non-pregnant bitches. Reprod. Dom. Anim. 40, 46-50.

Schäfer-Somi, S., Beceriklisoy, H. B., Budik, S., Kanca, H., Aksoy, O. A., Polat, B., Cetin, Y., Ay, S. S. and Aslan, S. (2008): Expression of genes in the canine pre-implantation uterus and embryo - implications for an active role of the embryo before and during invasion. Reprod. Dom. Anim. 43, 656-663.

Schäfer-Somi, S., Sabitzer, S., Klein, D., Tomaszewski, C., Kanca, H., Beceriklisoy, H. B., Kucukaslan, I., Agaoglu, A. R., Kaya, D., Ay, S. S. and Aslan, S. (2012): Is apoptosis a regulatory mechanism during early canine pregnancy? Reprod. Dom. Anim. 202, Suppl. 6, 169-172.

Sørensen, J. G., Christensen, T. N. and Loeschcke, V. (2003): The evolutionary and ecological role of heat shock proteins. Ecol. Lett. 6, 1025-1037.

Szczubiał, M., Wawrzykowski, J., Dąbrowski, R., Krawczyk, M. and Kankofer, M. (2017): Preliminary study on plasma proteins in pregnant and non-pregnant female dogs. Theriogenology 97, 1-8.

Ulutas, P. A., Musal, B., Kiral, F. and Bildik, A. (2009): Acute phase protein levels in pregnancy and oestrus cycle in bitches. Res. Vet. Sci. 86, 373-376.

Valdés, A., Holst, B. S., Lindersson, S. and Ramström, M. (2019): Development of MS-based methods for identification and quantification of proteins altered during early pregnancy in dogs. Proteomics 192, 223-232.

Vannucchi, C. I., Mirandola, R. M. and Oliveira, C. M. (2002): Acute-phase protein profile during gestation and diestrous: proposal for an early pregnancy test in bitches. Anim. Reprod. Sci. 74, 87-99.

Witkin, S. S., Kanninen, T. T. and Sisti, G. (2017): The role of Hsp70 in the regulation of autophagy in gametogenesis, pregnancy, and parturition. Adv. Anat. Embryol. Cell. Biol. 222, $117-127$. 